\title{
Social Science Subjects' Inclusion in the Main Curricular of Medical Students, Views from Nigeria
}

\author{
Ayodele John Oluropo \\ Sociology Unit, Department of Social Sciences, Crawford University, Igbesa, Nigeria \\ Email: ropojohn@yahoo.com
}

Received 1 July 2015; accepted 27 September 2015; published 30 September 2015

Copyright (C) 2015 by author and Scientific Research Publishing Inc.

This work is licensed under the Creative Commons Attribution International License (CC BY). http://creativecommons.org/licenses/by/4.0/

(c) (i) Open Access

\begin{abstract}
This paper discusses the training of medical students in the light of social science courses' inclusion in the curricula of medical students alongside with organ and academic approaches. The objectives of this study are twofold: 1) to share the data on the views of both faculty and students on the desirability of including social science courses in the main curricula of medical students' training in two medical schools; 2) to report the extent of social science course inclusion in the training of medical students in the curricula of the two medical schools. Results of the study showed faculty members disapproval of inclusion of social science subjects in the curricular for training medical students. However, students were of the opinion that there should be less of rigorous scientific approach and more of social science courses in their main curricular not just passing attachments.
\end{abstract}

\section{Keywords}

Social Science Subjects, Medical, Curricula, Students, Community

\section{Introduction}

There are three popular methods of academic instructions in the medical schools, these are: 1) academic discipline approach which places emphasis on such subjects as Anatomy, Biochemistry, Physiology, and Pathology; 2) organ system approach places emphasis on profound study of body organs such as cardiovascular, respiratory, nervous, and digestive system; and 3) problem based approach which is rooted on sound knowledge of social science subjects such as Psychology, Sociology, and Demography. Here they tend to group generation and transmission of knowledge to be acquired by students around problems such as chest pain, fever, malnutrition, 
and nutrition. Problem based learning is a WHO term used to determine the appropriateness of medical schools’ curricular in relation to Primary Health Care (PHC) or Community Based approach to health care delivery. It is defined as "learning that result in the process of working toward the understanding or resolution of a problem" (Barrows and Tamblyn, 1980) [1]. Social science subjects are the bedrock of problem based approach. The Flexner reform of the $20^{\text {th }}$ century endorsed the germ theory which was nothing short of empirical science which assumed that illness be explained (at least in principle) in terms of morphological, physiological and biochemical derangement and dysfunctions (Seldin, 1984) [2]. Physician's training in the developed countries is being pulled by two opposing forces, the "traditionalists" and the "modernists". These two protagonists fall along the issue of "hard sciences" as traditionalists and "minimum sciences with some problem based courses" as the modernists in the medical schools (Barrows and Tamblyn, 1980) [1]. According to Flexner Report of 1910 [3], it championed the biomedical approach to medicine. Flexner further argued that the biomedical approach could not address the health care needs of most of the population just only about $20 \%$ - $30 \%$ of the population health needs at any point in time (Ayodele, 2000) [4]. Health care services should be responsive to the health needs of the majority of the citizenry of a nation. In other words, medical care should respond to the patterns of diseases ravaging the population and it should be a right and not a commodity. The foregoing can only be achieved with appropriate dosage of social science subjects in the main curricula of medical schools.

\subsection{Objectives of the Study}

1) To investigate the extent of social science subjects' inclusion in the medical curricula of the University of Ibadan (traditional) and University of Ilorin (community oriented).

2) To investigate the views of both faculty members and students on the issue of social science inclusion in the training of medical students in the two medical schools.

\subsection{Statement of the Problem}

The Flexner Report of 1910 recommended the biomedical approach to medicine. He further argued that service function of medical schools especially the direct responsibility for patient care should be drastically reduced, otherwise the medical schools would not be able to fulfill its educational functions as a social agency for the generation and transmission of knowledge. The implementation of Primary Health Care (PHC) which is expected to be the key to health of Nigerians, emergence of disease such as HIV/AIDS which need more of support and care management at individual, family, and community levels has created for medical education a totally new approach to health services delivery and development in that it involves:

1) A total reorientation of health services, so that secondary and tertiary cares are geared towards supporting the first contact level of care.

2) A more equitable distribution of health resources-a situation where the curative health services gulp $80 \%$ of the health resources to manage health problems of $20 \%$ of the population certainly need re-visitation (Ayodele, 2000) [4].

3) A multi-sectoral approach to health care delivery.

4) Strong and active individual management of health services and health problems.

5) Strong community involvement and participation in health care services' delivery which may extend to ownership of such health services.

\subsection{Social Significance of the Study}

The physician in the biomedical model with rigorous science is likened to a person rescuing drowning people from a river, too busy to investigate why these people were falling into the river upstream (Brody \& Sobel, 1984) [5]. An old parlance is applicable here-_what one lacks cannot be given out”. It follows that before the foregoing problematic issues can be adequately handled, inclusion of social science subjects to training physicians be given prominence in the medical schools curricula. The diseases that are ravaging the population of the developing countries can better be managed by consistent skills acquired by doing or by a process which can be gotten through active application of social science subjects which represent the building blocks for Primary Health Care (PHC) and community health implementation and household levels reorientation regarding preventive health care measures and patterns of diseases. In 1991 for example the Fiji School of Medicine restructured 
the training of its medical students dividing its 7 year course into two phases. Students have the option of studying community oriented medicine for three years after which they may elect to undertake further hospital-based training to complete their medical degree. The course responds to the health needs of South Pacific and the local patterns of morbidity and mortality, rather than measuring itself against the curricula demands of the more developed neighbors Australians and New Zealand (Hill and Samsoni, 1993) [6].

\subsection{Theoretical Issues}

The rigidity of the training of medical students on the basis of Western educational system and standards can be traced to the elite paradigm. According to Mills (1959) [7] the elites are those who have the most of what there is to have, which is generally held to include money, power, prestige, as well as influence. Elites are also powerful; they are able to realize their duties as well as the duties of others beneath them. They are not merely following orders, they give orders, they are not merely bureaucrats but command bureaucracies. The instituted elites are rarely free of tensions; they come together only on certain coinciding points and only on certain emergence of crises. More powerful than factions, conflicts of policy, clashes of individual or group ambition, are the internal disciplines and community of interests that bind the elite together even across boundaries and nations. The major actors or stakeholders in medical education in Nigeria received their educational training from the curative oriented medical schools of the Western world. In these western countries, medicine is considered as a highly prestigious profession Blau et al. (1979) [8]. Also in the developing nations, the situation is not different. In a study of the elites carried out in Nigeria in 1971, medicine was rated highest by Nigerian elites followed by Law Smythe et al. (1971) [9]. Some of the features of the elites include controlling to their advantage, power, resources in all forms, wealth, status etc. These major actors in medical education who are responsible for molding physicians through the medical schools belong to favored group called members of the professional class - they are elites. These actors; essentially, are replicas of the advanced countries' professionals sharing information about control of health resources, status maintenance, privileges and special rewards (Alubo, 1986) [10].

\subsection{Literature}

In a review of about fifteen studies that compare various educational outcomes of community-oriented curricula with those of traditional or conventional program, startling findings have been documented (Schmit, et al., 1987) [11]. On clinical competence, there is some evidence that students from community-oriented perform somewhat better on tasks related to clinical competence. On career preferences, students of both expressed preferences for primary health care/community care specialties to some extent. By graduation the students in communityoriented track retained their initial interest in family medicine, whereas their peers in the conventional track had to some extent change their career preferences to internal medicine. On students' perception of the content of the curriculum and the instructional philosophy, students in community-oriented perceived the learning environment as definitely more flexible and meaningful, encouraged students interaction, and having a better emotional climate. Of note is the fact that considerable number of graduates who studied the conventional curricula felt that much attention had been given to bio-science and hospital based medicine. A situation where people from the developing countries cannot fare better, of what use is rigorous scientific medicine in lieu of reorientation of physician training regarding preventive health care measures and patterns of diseases. According to Henslin (2010) people born in the developing world, in their much shorter lives would face four major causes of illness and death: malaria (from mosquitoes), internal parasites (from contaminated water), diarrhea (from food and soil contaminated with human feces), and malnutrition. In fact over 30 million Nigerians systematically drop feces in the gutters and on the ground not only in the rural areas but even in urban centers. They practice open defecation such that it has become a major concern for the government (Punch Newspapers, $19^{\text {th }}$ Oct 2014) [12], (Ayodele, 2014) [13]. In the final analysis, schools with community-oriented curricula seem to be more successful in their attempt to produce physicians with community orientation, producing an environment that is congruent with general goals of university education to a larger extent than conventional schools. In 1988, after worldwide analysis starting from grassroots in every country, then passing through six Regional Conferences, a World Conference decided on the reforms now necessary in the education and training of doctors (Walton, 1993) [14]. In most countries there is a National Association for Medical Education, which is affiliated with World Federation for Medical Education (WFME). The WFME is the main global protagonist in implementing, first, community- 
oriented medical education and inclusion of social science subjects in medical curricula. The Nigeria version of WFME and WHO connection is called An Agenda for Action-Abuja declaration.

\section{Methodology}

\subsection{Research Design}

Study Location: The two medical schools selected for this study were purposively selected. The University of Ibadan, which was established in 1948 in all respects, was patterned after that of the University of London modeled along the lines of didactic lectures and patients oriented clinical teaching. The World Health Organization (WHO, 1979) [15] classified the medical school of the University of Ibadan as pursuing the traditional medical degree programs.

The University of Ilorin, the second medical school for this study was established in 1975. In 1987, the faculty of Health Sciences at the University, was designated a WHO collaborating center in Research and Manpower development on Community Oriented Educational Program. Thus, one can safely say that the Medical School of the University of Ibadan is traditional while that of University of Ilorin belongs to the innovative medical school group.

\subsection{Study Population}

Sampling method:

Sampling Medical students: At the University of Ibadan, 40 students were randomly selected from pre-clinical years, of 120 students and 60 students randomly selected out of a frame of 180 clinical and final year students. At the University of Ilorin, 40 students were randomly chosen out of 80 pre-clinical year students; and 60 out of 120 clinical and final year students.

Sampling Faculty Members: Any lecturer that teaches medical students for more than four units per session in hospital and classroom settings was considered as a faculty member. A sample frame containing 50 names for the University of Ibadan was developed, and by taking alternatively one out of every two, twenty-five faculty members were selected. As for the University of Ilorin, the faculty members that met our unit of study, were twenty-five, they were therefore served our questionnaires.

Participants in the FGD were representatives of the target groups-medical students, from part 1 to the final year. The homogeneity in terms of sex, age group, and year in the school was maintained. All the questions asked were derived from the questionnaires' administered for the study. An FGD group was made up of five students. Two FGDs were held in each university, one for preclinical and another for clinical, making four FGDs in all.

The in-depth interviews were conducted by having personal discussions with faculty members that have taught for ten years and above.

Data collection and Analysis: Data were collected during the school sessions in each of the medical schools. Both qualitative and quantitative methods were used; these include survey questionnaires to students, faculty members and policy makers. The qualitative methods utilized for data collection are Content Analysis for the curricula, Focus Group Discussion (FGD) and In-depth interview with lecturers and policy makers.

\section{Results}

\subsection{Questionnaires}

There were 166 medical students that responded by completing the questionnaires, but 34 students failed to complete and return the questionnaires. This represents $83 \%$ return rate and $17 \%$ failure rate. Twenty-seven faculty members responded by completing and returning the questionnaires. (18 from Ibadan and 9 from Ilorin) which is $54 \%$ return rate and $46 \%$ failure rate. Twelve of the twenty-five topmost policy makers interviewed returned completed questionnaires. The Community oriented rank a distant second with about half of those who preferred the organ system as can be seen on Table 1.

Faculty members from both universities have this common agreement of preferring organ system method of instruction to any other system. Thus, 55\% of Ibadan faculties and $66 \%$ of Ilorin faculties strongly support this method of instruction. It is ironic and interesting to observe Ilorin with strong Community-oriented medical 
schools financially supported by WHO preferring organ system, even with lower percentage than Ibadan for community oriented methods.

From Table 2 below, psychology and sociology were the preferred social science subjects for the entire sample. The table also indicates that the policy makers want management science to be included in the physician curriculum. In the study by (Shaldrake and Reid, 1972) 47 percent of staff accepted sociology as good for providing the necessary basis for systematic understanding of health problems.

Table 3 clearly indicates that most of the subjects in the same sample wanted social science courses to be introduced to medical students during the first and second year in the medical school. The table also shows that faculty members from Ilorin and the policy makers prefer the first year at the medical school to serve as the year of commencement. The faculty members from Ibadan seem to have opted for the second year.

\subsection{Content Analysis}

None of the Universities has included social science subjects in their curricular. In an effort to identify the closest approach to social science subjects inclusion in the curricular, the recommendation of WHO on problembased learning by teaching of Primary Health Care Components and activities were used as proxy measures for social science subjects inclusion in the curricular of the two medical schools. The following information on Table 4 and Table 5 emerged.

Table 1. Preferred method of instruction in teaching medical students by faculty members.

\begin{tabular}{ccccc}
\hline Universities & Academic discipline & Organ system & Community orientated approached & Total \\
\hline Ibadan & $3(17 \%)$ & $10(55 \%)$ & $5(28 \%)$ & $18(100 \%)$ \\
Ilorin & $2(22 \%)$ & $5(66 \%)$ & $2(22 \%)$ & $9(100 \%)$ \\
Total & $5(18 \%)$ & $15(56 \%)$ & $7(26 \%)$ & $27(100 \%)$ \\
\hline
\end{tabular}

Source: J.O. Ayodele (2000) [4] "Relevance of Physician training to Primary Health Care (PHC) in Nigeria” PhD dissertation. Faculty of Social Sciences, Department of Sociology. Obafemi Awolowo University Ile-Ife. Nigeria.

Table 2. Social science subjects recommended for inclusion in medical curriculum.

\begin{tabular}{|c|c|c|c|c|c|}
\hline \multirow{2}{*}{ Social science subjects } & \multicolumn{2}{|c|}{ Ibadan } & \multicolumn{2}{|c|}{ Ilorin } & \multirow{2}{*}{ Policy makeı } \\
\hline & Faculty & Student & Faculty & Student & \\
\hline Sociology & $32 \%$ & $29 \%$ & $33 \%$ & $25 \%$ & $30 \%$ \\
\hline Psychology & $33 \%$ & $31 \%$ & $25 \%$ & $23 \%$ & $25 \%$ \\
\hline Demography & $15 \%$ & $10 \%$ & $11 \%$ & $11 \%$ & $10 \%$ \\
\hline Economics & $11 \%$ & $2 \%$ & $10 \%$ & $8 \%$ & $5 \%$ \\
\hline Management science & $2 \%$ & $14 \%$ & $11 \%$ & $20 \%$ & $30 \%$ \\
\hline No response & $7 \%$ & $14 \%$ & $10 \%$ & $13 \%$ & \\
\hline Total & $100 \%$ & $100 \%$ & $100 \%$ & $100 \%$ & $100 \%$ \\
\hline
\end{tabular}

Source: J.O. Ayodele (2000) [4] "Relevance of Physician training to Primary Health Care (PHC) in Nigeria" PhD dissertation. Faculty of Social Sciences, Department of Sociology. Obafemi Awolowo University Ile-Ife. Nigeria.

Table 3. Year at which social science subjects should be included in the medical curriculum.

\begin{tabular}{|c|c|c|c|c|c|}
\hline \multirow{2}{*}{ Recommended year } & \multicolumn{2}{|c|}{ Ibadan } & \multicolumn{2}{|c|}{ llorin } & \multirow{2}{*}{ Policy maker } \\
\hline & Faculty & Student & Faculty & Student & \\
\hline Year I & $29 \%$ & $36 \%$ & $45 \%$ & $25 \%$ & $42 \%$ \\
\hline Year II & $40 \%$ & $29 \%$ & $22 \%$ & $35 \%$ & $25 \%$ \\
\hline Year III & $6 \%$ & $1 \%$ & $11 \%$ & $18 \%$ & $8 \%$ \\
\hline Final year & $10 \%$ & $14 \%$ & $11 \%$ & $10 \%$ & - \\
\hline No response & $15 \%$ & $20 \%$ & $11 \%$ & $12 \%$ & - \\
\hline Total & $100 \%$ & $100 \%$ & $100 \%$ & $100 \%$ & $100 \%$ \\
\hline
\end{tabular}

Source: J.O. Ayodele (2000) [4] "Relevance of Physician training to Primary Health Care (PHC) in Nigeria” PhD dissertation. Faculty of Social Sciences, Department of Sociology. Obafemi Awolowo University Ile-Ife. Nigeria. 
Table 4. Community activities (community oriented courses) in school curricular and year of commencement (content analysis).

\begin{tabular}{lcc}
\hline Community activities/community oriented courses & University of Ibadan & University of Ilorin. \\
\hline Making home visits & $4^{\text {th }}$ year & $2^{\text {nd }}$ year till $6^{\text {th }}$ year \\
Meeting community leaders & & \\
Visiting rural families & \\
Visiting urban families & & \\
Working in local health clinics & $4^{\text {th }} \& 5^{\text {th }}$ year (once) & Yearly from $2^{\text {nd }}$ year \\
Conducting epidemiological studies & $4^{\text {th }}$ year & $1^{\text {st }}$ year till $6^{\text {th }}$ year \\
Study major health problems in Nigeria & $3^{\text {rd }}$ year & \\
Study major diseases of Nigeria & \\
Provision of health education & \\
Food and nutrition & \\
Safe water supply & \\
MCH \& family planning & \\
Immunization \& endemic diseases prevention & \\
\hline
\end{tabular}

Source: J.O. Ayodele (2000) [4] "Relevance of Physician training to Primary Health Care (PHC) in Nigeria” PhD dissertation. Faculty of Social Sciences, Department of Sociology. Obafemi Awolowo University Ile-Ife. Nigeria.

Table 5. Mode of instruction in school curricula (content analysis) length of school curricular.

\begin{tabular}{ccc}
\hline Modes of instruction & Ibadan & Ilorin \\
Formal lecture & 12345 years & 123456 years \\
\hline Small group discussion community oriented & $\mathrm{XXXX}$ & $\mathrm{XXXXX}$ \\
Small group tutorial community oriented & $\mathrm{XX}$ & $\mathrm{XXXXXX}$ \\
Field work visits community oriented & $\mathrm{X}$ & $\mathrm{XXXXXX}$ \\
Laboratory group community oriented & $\mathrm{X}$ & $\mathrm{XXXXXX}$ \\
Self-directed studies community oriented & $\mathrm{XXX}$ & $\mathrm{XXXXX}$ \\
\hline
\end{tabular}

Source: J.O. Ayodele (2000) [4] "Relevance of Physician training to Primary Health Care (PHC) in Nigeria” PhD dissertation. Faculty of Social Sciences, Department of Sociology. Obafemi Awolowo University Ile-Ife. Nigeria.

As can be seen from these two tables, one can see that the university of Ibadan seems to be very traditional, in that elements of PHC and community oriented courses only get minimal attention when the medical students have almost completed their courses, during this period such courses are rarely taken seriously by the students. On Table 5, one can also see that the University of Ibadan heavily emphasizes formal lecture approach which rarely give prominence to community oriented approach or inclusion of social science subjects.

\subsection{Focus Group Discussion (FGD)}

One can obtain some information about the bias for scientific high technologic medicine of the faculty members from their students. An FGD participant (pre-clinical student from Ibadan) has the following to say:

"There is a need to be less theoretical in the teaching of medical students Practical work in the communities towards health problems solutions should be given more attention nowadays."

Another FGD participant (Clinical student from Ilorin has this to say:

"Teachers must be reoriented to reflect the ideals of the communities' importance towards health problems solutions in their teaching of medical students.”

One can see from the FGD Table 6 that medical students from both universities were of the strong desire that social science subjects should be included in their "main curricula. Efforts to reform the medical education of the country to reflect diseases patterns, and community driven program should start with the training of medical students, because they can be molded, they are not yet ossified in their ways like their teachers. For example on depersonalization of patients, some medical students start medical schools with lofty motives desiring to "treat 
Table 6. Reaction of groups to social science subjects inclusion into medical curriculum—medical students.

\begin{tabular}{|c|c|c|c|c|}
\hline \multirow{2}{*}{ Statements on social science subject } & \multicolumn{2}{|c|}{ Ibadan } & \multicolumn{2}{|c|}{ Ilorin } \\
\hline & Pre-clinical & Clinical & Pre-clinical & Clinical \\
\hline Psychology should be included & + & + & + & + \\
\hline Sociology should be included & + & + & + & + \\
\hline Psychology inclusion should commence $2^{\text {nd }}$ years & + & & + & + \\
\hline Sociology inclusion should commence $2^{\text {nd }}$ years & + & & + & + \\
\hline Psychology inclusion should commence $4^{\text {th }}$ years & & + & & \\
\hline Sociology inclusion should commence $4^{\text {th }}$ years & - & - & - & - \\
\hline Key & & & & \\
\hline $\begin{array}{l}\text { Group supported the statement }+ \\
\text { Group did not support the statement - }\end{array}$ & & & & \\
\hline
\end{tabular}

Source: J.O. Ayodele (2000) [4] "Relevance of Physician training to Primary Health Care (PHC) in Nigeria” PhD dissertation. Faculty of Social Sciences, Department of Sociology. Obafemi Awolowo University Ile-Ife. Nigeria.

the whole person” it does not take long for them to depersonalize patients. Unconscious patients, the dying, and the dead are transformed into special objects for practicing their skills (Berger et al., 2002) [16].

\section{Discussion}

From all available information, the scientific core courses in the medical schools, such as Biochemistry, Physiology, Anatomy, Pharmacology etc., remain essentially unaltered and the time allotted them has neverbeen reduced. This stand is shared by most faculty members of both Universities. Their students that are more forthcoming suggested that a balance must be struck between hard core scientific orientation and community oriented courses.

The following quotes from FGD participant (clinical student from Ilorin) underscored the above view:

“The Nigeria Medical Association (NMA) and National University Commission (NUC) must be able to strike a balance between rigid scientific orientation which aims at international recognition of Nigeria medical graduates and satisfaction of our medical and health needs using communities' solution and strategies”.

The foregoing is in tandem with the suggestions of (Abdulraheem et al., 2010) [17] that community based teaching should be introduced very early in the medial schools and must continue throughout the education programme. That mission and objectives of medical education should be determined by priority health needs, and health problems prevalent in the community and the country. Medical education needs to be planned and implemented with full awareness of the aims and demands of the health care services. Community health care, said Abdulraheem should feature prominently in the curriculum encompassing primary health care components. Special emphasis should be given to priority community health needs and issues.

Health and health services cannot be separated from the larger socio-economic and environmental circumstances in which people live. Estimates using the 2012 National HIV/AIDS and Reproductive Health Survey, the national HIV prevalence of 3.4\% translates to about 6 million Nigerians are infected with the virus in 2012 . Lately an increasing number of children are being either infected through Mother To Child (MTC) or are losing one or both adult parents to the disease (NACA, 2001) [18]. However, HIV positive mothers are being given drugs for themselves and their babies to prevent transmission of HIV to her children. Many positive mothers are not being captured. Overall coverage for ARV drug use for PMTCT during pregnancy, delivery and after pregnancy for child was 52\%; 46\%; and 27\% respectively; these figures are too low (NARHS plus II, 2012) [19]. The snowballing effects of this particular epidemic and others such as high IMR 89/1000 and under-5MR 162/1000 in some parts of the country is quite worrisome (NHRHS plus II, 2012) [19]. All the foregoing and many bad pictures of Nigerian health statuses put into question the issue of reductionism associated with medical schools curricular. One of the great difficulties facing health care and therefore medical education is how to integrate more closely with other sectors of the community and national development. Inclusion of Social Science subjects in the medical curricular is a pre-requisite for this. Currently, educational and training programs frequently have become irrelevant and dysfunctional in relation to local needs. The structure of the curriculum, the interests and attitudes of the faculty, the social status of the specialists, militate against student physician 
acquiring a live long interest in the community.

However, in-depth interview and content analysis clearly pointed out that many faculty members are not prepared to integrate social science subjects with the main curricula of medical schools. Particularly at Ibadan, only six weeks are allotted to teaching PHC and community oriented courses (the proxy measures for community oriented courses) throughout five years of academic career of medical students. The qualitative method of inquiry further yielded information about the condition put up by the faculty members for accepting PHC and community oriented courses as part of the curricula; and that is, to allow all the traditional courses to remain virtually untouched in terms of time allotted to them; they fear that reduction in time allotted for the core courses will lead to dilution of physician training. Again the dichotomy between the preventive and curative also comes into prominence here, as the faculty members from Public, Community, Social and Preventive Medicine continuously press for inclusion of social science courses, while those from Clinical, Pathology, Biochemistry and Pure Science often resist with resolved abandon. It was also observed that the original core courses in the two Universities remain essentially the same just as Stacy Day observed several years ago that medical schools curricula all over the world had remained and unchanged for more than a century (Day, 1984) [20]. The PHC courses that one finds in their curricular were being treated as attachments leading to the extension of the period of training for medical students. This is exactly what was happening at the University of Ilorin which the WHO currently used as model for community based medical school.

If the health of the nation (Nigerians) are left in the hands and under the control of curative oriented physicians alone, the country will be laying foundations for future disaster and trouble for generation yet unborn. Learning from the Western World where unbridled professionalization of medicine has been allowed before they could wake up form their slumber, people are already paying with their lives in the following ways:

1) The social inequality fueled by curative medicine, where medical care is no longer a right but commodity, the rich will have access to one type of care and the poor to another (Henslin, 2010) [21].

2) Mal practice Lawsuits and defencive medicine has become the order of the day. Doctors are not excused formaking mistakes. In order to protect themselves, physicians practice defencive medicine. They consult with colleagues and order various tests not because the patient need them but because the doctors want to leave paper trail in case they are sued. These consultations and tests-done for doctors' benefits not the patients'-run medical bills up even higher out of the reach of ordinary folks (Henslin, 2010) [21].

3) Medical incompetence- - "A woman went into the hospital with a problem with her lungs hersurgeon did a hysterectomy". A man supposed to have a circumcision, but the surgeon mistakenly remove both testicles. The foregoing are actual cases (Steinhauer and Fessenden, 2001) [22], (Seiden and Barach, 2006) [23]. There are about 4000 wrong patients wrong sides, or wrong procedure, surgeries a year in the USA (Senders and Kenzchi, 2008) [24].

4) Conflict of interest-One doctor received $\$ 300,000.00$ for recommending to other doctors that they should prescribe a particular drug to their patients (Peterson, 2003) [25]. Other physicians publish research in medical journal on products in which they are investors (Abelson, 2008) [26]. Some drug companies ghost-write articles for medical journals that present research about how good their drugs are —and then look for doctors to list as authors (Henslin, 2010) [21].

5) Medical Fraud—Guidant Corporation discovered that its heart defilebrators which are surgically implanted in patients could short circuit and kill patients. Yet the company kept selling the defective equipment while it developed a new model killing many patients (Meier, 2005, 2006) [27] [28]. Bayer found that its drug had a few side effects-it could increase the risk of stroke, damaged kidneys, cause heart failure, and death. Bayer did not warn the doctors that they might be killing their patients. In Bayers own words it "mistakenly did not inform" the FDA of the study that reveal the findings (Harris, 2006) [29]. Yet Bayers made a whopping sale of \$200 million dollar sales of the killing drug.

6) Sexism in medicine-The case of hysterectomy in women is very worrisome issues. Male doctors often go for hysterectomy like saleman out to sell automobile. Uterus and ovaries argued male doctors are "potentially disease producing". They also argue that, those organs are unnecessary after the child bearing years, so why not remove them. The more hysterectomies performed the more money for the doctors (Broder et al., 2000) [30].

7) Medicalization of the Society-Normal aging process such as wrinkles, balding, sagging buttocks and chins, shrinking or falling breasts, all have become medical problems which must be treated by physicians. Conflict sociologists would argue that such medicalization indicate growing power of the medical establishment. The more conditions of life that physician can medicalize, the greater their profit \& power (Henslin, 2010) [21]. 
Currently, there is deafening cry in the USA, for reform of their health system which is being predicated on the reform of medical education, with particular emphasis on physician training (Kenton Voorhees et al., 2013 [31]; Particia Salber, 2012 [32]; Shannon (O’Brien) Breymaier 2013 [33]; Thomas J. Lawley MD et al. [34] http://www.aamc.org/meded/icine/about.html.

\section{Conclusions}

If PHC goals, community and household level management of the dreaded HIV/AIDS, and control of the bouncing back tuberculosis, sticky malaria endemicity, increased bouncing back of other infectious diseases, and increasing nutrition related diseases are to be achieved to improve the health status of the people which are currently abnormally poor in Nigeria, then there is a need to overhaul urgently the training of medical doctors.

The re-training and changing of the curricular of the allied health personnel such as nurses, and sanitarians just will not do, and the team leader—physician—must be reoriented. There are two possible ways: Firstly, the subjects to be included must be made mandatory through a realistic and well-modulated curriculum emphasizing the inclusion of social science courses with medical students spending an extra year before going for their residency. The second approach is to ensure mandatorily that all physicians have a first degree in health sciences, pure sciences with heavy dosage of prescribed, and social science subjects for all universities' medical schools before going for medical degree which should not last more than four years.

Without revolutionary changes in medical education, developing countries according to the late Professor Ransome Kuti will continue to train doctors to solve the health problems of other countries other than their own; they will continue to seek international recognition for their medical graduates which only permits them to emigrate at the earliest opportunity (Kuti in Abuja, 1989) [35], (Nwariaku, 2010) [36]. This view of the late doyen of medicine aptly captures the principal concern that is informed in this study, and it is the view of the author, which is an anachronistic scenario or trend that needs to be addressed realistically and urgently.

\section{References}

[1] Barrow, H.S. and Tamblyn, R.M. (1980) Problem Based Learning: An Approach to Medical Education. Springer Publishing Company, New York.

[2] Seldin, O.W. (1984) The Medical Model: Biomedical Sciences as the Basis of Medicine. In: Rhee, P., et al., Eds., Nations Health Boyd and Frassen Publishing Co., USA, 55-62.

[3] Flexner, A. (1910) Medical Education in United States and Canada: A Report to the Carnegie Foundation for the Advancement of Teaching. Bulletin No. 4, New York.

[4] Ayodele, J.O. (2000) Relevance of Physician Training to Primary Health Care (PHC) in Nigeria. PhD Dissertation, Obafemi Awolowo University, Ile-Ife.

[5] Brody, H. and Sobel, D.S. (1984) A System View of Health and Diseases. In: Rhee, P., et al., Eds., Nations Health Boyd and Fraser Publication Company, San Francisco, 62-80.

[6] Hill, P. and Samisoni, J. (1993) Two Models of Primary Health Care Training. Medical Education, 27, 69-75. http://dx.doi.org/10.1111/j.1365-2923.1993.tb00231.x

[7] Mills, W.C. (1959) The Power Elite. Oxford University Press, London.

[8] Blau, P., et al. (1979) The Professional and Academic Context of Professional Schools. In: Merton, R.K., et al., Eds., Qualitative and Quantitative Social Research, The Free Press, New York.

[9] Smythe, H.H. and Smythe, M.M. (1977) The New Nigeria Elites. Standards University Press, California.

[10] Alubo, S.O. (1988) The Political Economy of Doctors' Strikes in Nigeria: A Marxist Interpretation. Social Science and Medicine, 22, 467-477.

[11] Schmidt, H.G., Dauphinee, W.D. and Patel, V.L. (1987) Comparing the Effects of Problem Based and Conventional Curricular in an International Sample. Journal of Medical Education, 62, 305-315.

[12] Punch News Papers, 19 October 2014.

[13] Ayodele, J.O. (2014) Community Based Approach for Effective Garbage and Flood Control in Nigerian Cities. Scottish Journal of Arts and Social Science, 18.

[14] Walton, H. (1993) A Global Strategy for Medical Education: Partners in Reform. Medical Education, 27, $394-398$. http://dx.doi.org/10.1111/j.1365-2923.1993.tb00291.x

[15] WHO (1979) World Directory of Medical Schools. Fifth Edition, Geneva. 
[16] Berger, J.T., Rosner, F. and Cassell, E.J. (2002) Ethics of Practicing Medical Procedures on Newly Dead and Nearly Dead Patients. Journal of General International Medicine, 17, 774-778. http://dx.doi.org/10.1046/j.1525-1497.2002.11139.x

[17] Abdulraheem, I.S., Musa, O.I. and Oladipo, A.R. (2010) Emerging Issues in the Practice of University Learning and Teaching Challenges and Way Forward for Improving Medical Training in Nigeria. Educational Research, 1, 691-699. http://www.interestjournals.org/ER

[18] NACA (2001) FMOH Federal Secretariat. National Action Committee on AIDS, Abuja.

[19] NARHS plus II 2012 (2013) National HIV/AIDS and Reproductive Health Survey. Federal Republic of Nigeria FMOH, Abuja.

[20] Day, S. (1984) Health Communication: A Publication of the International Foundation for Bio Social Development and Human Model. New York, 198-199.

[21] Henslin, I.M. (2010) Sociology: A Down-to-Earth Approach. Pearson, New York, Tokyo and London.

[22] Steinhauer, J. and Ford, F. (2001) Medical Retreads; Doctor Punished by State but Prized at the Hospitals. The New York Times, March 27, 2001.

[23] Seiden, S.C. and Paul, B. (2006) Wrong Side/Wrong-Site Wrong Procedure and Wrong Patient Adverse Events. Archives of Surgery, 141, 931-939. http://dx.doi.org/10.1001/archsurg.141.9.931

[24] Senders, J.W. and Regine, K. (2008) The Egocentric Surgeon or the Roots of Wrong Side Surgery. Quality and Safety in Health Care, 17, 396-400. http://dx.doi.org/10.1136/qshc.2007.023564

[25] Peterson, I. (2003) 1993 Deal for Indian Casino Is Called Model to Avoid. The New York Times, June 30, 2003.

[26] Abelson, R. (2008) Financial Ties Cited as Issues in Spine Study. The New York Times, January 30, 2008.

[27] Meier, B. (2005) Defective Heart Devices Force Some Scary Medical Decisions. The New York Times, June 20, 2005.

[28] Meier, B. (2006) Guidant Debated Device Peril. The New York Times, January 20, 2006.

[29] Gardiner, H. (2006) FDA Says Bayer Failed to Reveal Drug Risk Study. The New York Times, September 30, 2006.

[30] Broder, M.S., Kanouse, D.E., Mittman, B.S. and Bernstein, S.J. (2000) The Appropriateness of Recommendations for Hysterectomy. Obstetrics \& Gynecology, 95, 199-205. http://dx.doi.org/10.1016/S0029-7844(99)00519-0

[31] Voorhees, K.I., Prado-Gutierrez, A., Epperly, T. and Dirkson, D. (2013) A Proposal for Reform of the Structure and Financing of Primary Care Graduate Medical Education. Family Medicine, 45, 164-170.

[32] Patricia, S. (2012) Fixing Health Care Include Reforming Medical Education. Medical Education, April 12, 2012.

[33] Shannon (O’Brien), B. (2013) American Medical Association (AMA) Announces \$10 Million Initiative to Change the Way Future Physician are Trained. www.changeded.org

[34] Thomas, J.L., et al. (2013) Medical Education: Time for Reform. http://www.aamc.org/meded/iime/about.htm

[35] African Ministerial Consultation (1989) Medical Education in Africa: An Agenda for Change. Highlights of an African Ministerial Consultation. Abuja.

[36] Nwariaku, F.E. (2010) Performance of Medical Graduates within and outside Nigeria. Nigeria Medical Journal, 51, 92-94. 